\title{
Utilização da Biometria em Transportes Públicos
}

\author{
Bruno R. Baggieri*. Carlos M.s de Souza**. \\ Mariana G. L. K. Magioni**. Adan L. Pereira***
}

\author{
* Graduando em Engenharia da Computação, Faculdade Brasileira - Multivix Vitória. \\ Rua José Alves, $n^{\circ}$ 135, Goiabeiras, Vitória - ES, 29075-080 (e-mail: brunokbo@gmail.com). \\ ** Graduando em Engenharia Elétrica, Faculdade Brasileira - Multivix Vitória. \\ Rua José Alves, $n^{\circ}$ 135, Goiabeiras, Vitória-ES, 29075-080 (e-mails: cmsouza1998@gmail.com; marianalkm@gmail.com) \\ *** Mestre em Energia, Faculdade Brasileira - Multivix Vitória. \\ Rua José Alves, $n^{\circ}$ 135, Goiabeiras, Vitória - ES, 29075-080 (e-mail: adanlucia@gmail.com)\}
}

\begin{abstract}
This paper intends to present an alternative to the method of payment for public transportation tickets. The analysis begins with the understanding of the function of this type of transport in society and the methods of biometric analysis. The methodology includes an exploratory research about the aforementioned points and the development of a prototype composed of a WEB interface integrated with a system developed in the platform Arduino, responsible for the intelligent biometric system. The results were satisfactory in terms of financial control and flow of different passengers when using the developed system.
\end{abstract}

\begin{abstract}
Resumo: Este trabalho tem o propósito de apresentar uma alternativa ao método de pagamento das passagens do transporte público. A análise inicia-se no entendimento da função deste tipo de transporte na sociedade e os métodos de análise biométrica. A metodologia inclui uma pesquisa exploratória acerca dos pontos citados anteriormente e no desenvolvimento de um protótipo composto por uma interface $W E B$ integrada com um sistema desenvolvido na plataforma Arduino, responsável pelo sistema biométrico inteligente. Os resultados foram satisfatórios no âmbito de controle financeiro e de fluxo de diferentes passageiros ao utilizar o sistema desenvolvido.
\end{abstract}

Keywords: Public Transportation; Smart Biometric System; WEB Interface; Arduino; Financial Control.

Palavras-chaves: Transporte Público; Sistema Biométrico Inteligente; Interface WEB; Arduino; Controle Financeiro.

\section{INTRODUÇÃO}

A identificação de indivíduos é de suma importância desde os primórdios. Tal ação é justificada para atribuir direitos, deveres, posses, fatos, dentre outras qualificações e ligações com acontecimentos e fatos, além de criar a distinção entre os diferentes indivíduos. A identificação de cada ser humano, como quaisquer técnicas inventadas pelo homem, passou por diversas evoluções. A individualização através do uso de nomes e sobrenomes foram os primeiros modelos de distinção utilizado, porém tais métodos são limitados e de fácil manipulação. Diversos métodos, como os documentos de identidade, emitidos por órgãos de segurança pública, também são questionáveis, pois há o risco de falsificação dos mesmos. (SILVA, 2018).

Apesar da rapidez na identificação utilizando técnicas mais arcaicas, como a identificação visual, a assinatura ou a utilização de cartões, por exemplo, são métodos suscetíveis a falhas. A identificação visual, quando não são realizadas por máquinas e softwares, ficam sujeitas ao erro humano. Os cartões, independente do seu tipo, podem ser clonados, bem como as assinaturas podem ser falsificadas (MARQUES et al., 2017).

Traçando um paralelo com a atualidade, visualiza-se que o problema de identificação de diferentes indivíduos ainda necessita de diversos aperfeiçoamentos. Enquanto na antiguidade era necessário identificar cada ser humano pessoalmente ou em documentos de papel, depara-se na necessidade de identificar o usuário através de dispositivos eletrônicos. Ao analisar-se a sociedade atual percebe-se que a segurança em sistemas de informações é de suma importância, visto a grande carga de dados presente nestes sistemas (SILVA, 2018).

A biometria faz referência a utilização de características físicas e comportamentais dos seres humanos para fins de identificação. Pode-se citar a face, a íris, a retina, a voz e a impressão digital como exemplos de características usadas. A impressão digital é uma das características mais seguras, pois até mesmo em gêmeos idênticos a impressão é diferente, bem como não costuma sofrer alterações durante o tempo de vida do indivíduo (LOPES, 2017). A biometria de impressões digitais é utilizada em ações policiais (para facilitar os processos de identificação em ações), em urnas eletrônicas 
(para permitir o exercício do voto), no sistema carcerário (para identificação dos presos) e em terminais de autoatendimento (FERREIRA et al., 2017).

\section{O TRANSPORTE PÚBLICO}

O transporte público é o meio mais abrangente e de suma importância para locomoção na sociedade atual. Encaixa-se nesta definição os veículos conduzidos pelos itinerários das linhas em horários pré-estabelecidos, utilizado por diversas pessoas através da venda e compra de passagens (FERRAZ e TORRES, 2003; CONCEIÇÃO, 2016).

O fornecimento deste tipo de transporte é realizado por órgãos públicos ou empresas privadas, baseadas no sistema econômico e social capitalista. Neste sistema há o incentivo na busca pelo lucro, incentivando a monetização de atividades exercidas (SCHUMPETER, 2017). Obviamente o sistema público de transportes também passa por este processo, possuindo diversos meios de pagamento por parte do seu utilizador, incluindo pagamento em espécie ou através da utilização de cartões de radiofrequência.

É notável o crescimento de casos de assaltos nesta modalidade de transportes. Na abrangência do estado do Espírito Santo, por exemplo, foram registrados 836 casos de roubos a transporte coletivo no ano de 2017 e 562 casos no ano de 2018 (SSP, 2019). Algumas tentativas de melhora na segurança deste transporte como a mudança no estilo das catracas, por exemplo, são feitas, mas sem nenhuma melhora efetiva e, em alguns casos, são reprovadas pela Agência Brasileira de Normas Técnicas por apresentarem problemas como altura maior que a permitida ou por bloquearem saídas de emergência.

\section{A AUTOMAÇÃO E O ARDUINO}

Os processos de automação buscam estruturar diversas atividades humanas, para que posteriormente, essas tarefas sejam transferidas para as máquinas. A automação em si é a disponibilidade de processos e elementos que possam reunir e organizar diversas tarefas para que haja o ganho de produtividade e minimização da ação humana. Sistemas autônomos possuem maior precisão e armazenamento de informações (MEIER e DE MELO, 2018).

O Arduino é umas das ferramentas que auxiliam na automação. É uma plataforma open-source de prototipagem eletrônica, que analisa entradas e saídas do dispositivo e seus componentes. Por possuir uma arquitetura simples, possui baixo custo. Para superar suas limitações, foram criados os shields: placas auxiliares acopladas ao Arduino que tornam possível o incremento de novas funções. São exemplos de shields: receptores GPS, display LCD, módulo de radiofrequência, módulo wi-fi, dentre outros. O Arduino utiliza sua própria IDE, com linguagem de programação baseada na linguagem $\mathrm{C}$, e também possui código aberto, possibilitando maior customização (AZEVEDO et al., 2018).

As linguagens de programação são um conjunto de recursos com o propósito de construir programas específicos seguindo um conjunto de regras que garantem a implementação com qualidade apropriada. Para a montagem do programa utilizado neste projeto utilizou-se: HTML, uma linguagem de marcação que permite a construção de páginas $W E B$; CSS, é uma linguagem de estilo, responsável pela formatação dos elementos através de mudança de cor de fundo, estilos de texto, dentre outras características; PHP, permite a interação do sistema com o usuário através de comandos lógicos, formulários, parâmetros, etc.; JavaScript, responsável por garantir um nível de interatividade às páginas $W E B$; e técnicas de banco de dados (GEMMER e MUELLER, 2017).

\section{METODOLOGIA E DESENVOLVIMENTO DO SISTEMA PROPOSTO}

A definição dos passos necessários para sintetizar as informações da literatura e então apresentar argumentos válidos para o desenvolvimento da mobilidade urbana sustentável frente a utilização dos sistemas de biometria, necessita de ser organizada segundo os termos técnicos da metodologia científica. Dessa forma, a natureza da pesquisa deste trabalho pode ser classificada como aplicada ou prática, pois, segundo Gil (2002) essa categoria de pesquisa busca gerar conhecimentos para aplicação prática dirigida à solução de problemas específicos, que no caso deste trabalho consiste em desenvolver um sistema que irá possibilitar a melhor identificação dos usuários do transporte público, com a utilização da biometria, e dessa forma, evitar a circulação de dinheiro em espécie pelo transporte público.

\subsection{Aspectos da Solução Proposta}

Com o intuito de melhorar a utilização do transporte público, a utilização de benefícios e fornecer maior segurança aos utilizadores e empregados deste sistema, apresenta-se a proposta de utilização da biometria através da impressão digital.

O sistema é composto por duas partes: leitor biométrico associado ao módulo wi-fi ESP8266, ao display LCD e um servomotor; e o sistema $W E B$ de recarga e cadastro de novos usuários. A adoção destes sistemas permitiria a modificação da estrutura interna de roletas presente nos veículos e até mesmo substituir a função do cobrador, trabalhador responsável por receber os pagamentos e liberar a roleta.

\subsection{Desenvolvimento do Sistema WEB}

Para utilizar o sistema de biometria, o usuário deve estar cadastrado no sistema $W E B$. Neste sistema o usuário insere os dados necessários para sua identificação e acesso à benefícios. Os dados solicitados são: nome completo, foto (para identificação do usuário em eventuais necessidades), sexo, data de nascimento, nome da mãe, nome do pai, informações de endereço, telefone, e-mail, CPF e senha de acesso ao sistema.

Em alguns municípios brasileiros, como Vitória no Espírito Santo por exemplo, determinam por lei que estudantes e idosos possuam desconto nas tarifas de transporte público, sendo $50 \%$ e $100 \%$ de desconto, respectivamente. As 
informações utilizadas no sistema, como fluxo de cadastro e tarifas serão baseadas no município citado neste parágrafo, no ano de 2018.

Os alunos que desejam obter o benefício do desconto na tarifa do transporte público necessitam apresentar aos órgãos responsáveis um documento, assinado pela instituição de ensino. Com o objetivo de desburocratizar e agilizar este processo, que atualmente é feito de forma presencial e com documentos físicos, o sistema também foi preparado para receber esta demanda. Para isto as instituiçõos devem se cadastrar no sistema preenchendo o formulário com os seguintes campos: nome e CPF do responsável pela instituição, CNPJ e nome fantasia da instituição de ensino, senha de acesso ao sistema, data final do período letivo do ano do cadastro, telefone, e-mail de contato e informações de endereço.

Levando em consideração as informações dispostas acima pode-se identificar quatro diferentes atores dentro do sistema, sendo estes: usuário comum, idoso, aluno e a instituição de ensino. Esta diferenciação é importante para as ações de débito e crédito de passagens, além da comprovação de conformidade de utilização de benefícios.

Quando um usuário classificado como usuário comum ou idoso realiza o login no sistema utilizando seu CPF e senha, ele é redirecionado para a tela principal, onde serão apresentados: nome e foto do usuário, opção de compra de passagens, quantidade de passagens, quadro de atividades recentes (composto também de informações a respeito de compras e outras solicitações), e por fim, o botão de logout. Este ator também pode realizar, através dos itens de menu presentes na tela:

- Comprar passagens: basta apenas clicar no botão "Comprar Passagens", informar a quantidade de passagens que deseja comprar e confirmar a compra, gerando, posteriormente, um boleto para pagamento.

- Atualizar Perfil: no item de menu do lado direito denominado "Perfill", o usuário pode visualizar e alterar suas informações pessoais. O CPF não pode ser alterado, pois trata-se de uma primary key, ou seja, é o identificador único da tabela que armazena as informações dos usuários.

- Visualizar Compras Antigas: logo abaixo do item de menu "Perfil", há a opção "Compras Antigas", que permitirá o usuário a visualização de todas as compras realizadas dentro do sistema.

Para os usuários classificados como instituição de ensino, a ação de login é realizada utilizando o CPF do responsável e a senha cadastrada. Caso as informações estejam corretas e cadastradas, o sistema apresentará uma tela com as seguintes informações: nome do responsável e da instituição, número de cursos cadastrados, quantidade de alunos que utilizam o sistema, número de solicitações de aprovação de comprovantes escolares, quadro de atividades recentes (composto também por informações de solicitações de aprovação do comprovante escolar), e o botão de logout. As instituições de ensino também possuirão outras três ações distintas no sistema, além das citadas. São elas: atualizar seu próprio perfil através do item de menu "Perfil", presente na tela principal; aprovar os comprovantes solicitados e preenchidos pelos alunos; gerenciar os cursos ofertados.

Os alunos cadastrados no sistema serão redirecionados para uma tela parecida com a tela dos usuários comuns, com a diferença da presença da aba "Dados Escolares". Nesta aba é possível visualizar as informações cadastradas no primeiro acesso ao sistema e informações como a data limite da recarga (definida como o último dia letivo da instituição) e a situação do comprovante escolar. No primeiro acesso são solicitadas informações sobre a instituição de ensino como: nome da instituição, curso, turma, turno e série. O sistema classificará os estudantes como usuários comuns até que os mesmos cadastrem seus dados escolares e sejam aprovados por suas respectivas instituições de ensino.

\subsection{Leitor Biométrico}

Para a parte física do projeto, utilizou-se o microcontrolador Arduino e o módulo leitor biométrico óptico digital. Este módulo funciona como um leitor biométrico comum: ao cadastrar uma impressão digital, o leitor cria arquivos de imagens que são usadas em leituras posteriores responsáveis por identificar o usuário. O esquemático do circuito montado está discriminado na Fig. 1, apresentada a seguir.

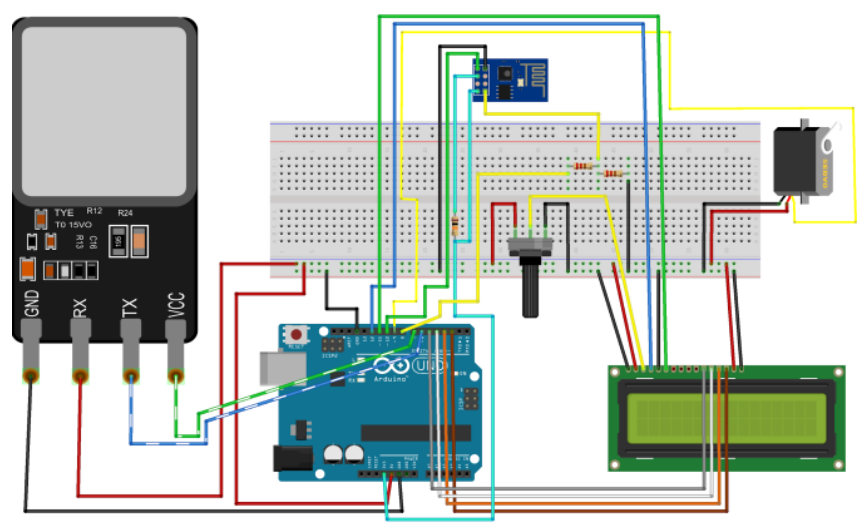

\section{Fig.1 Circuito Montado}

Obteve-se como resultado final o protótipo apresentado na Fig. 2 a seguir. Utilizou-se um monitor LCD (funcionando como uma interface entre o sistema e o usuário), um potenciômetro (para regular a corrente fornecida ao monitor LCD), um servomotor (para representar o sistema de liberação das catracas), um módulo biométrico (para leitura das impressões digitais), um módulo ESP8266 (para conexão do circuito desenvolvido no Arduino com a interface WEB) e três resistores (para limitar a tensão de funcionamento do módulo ESP8266). 


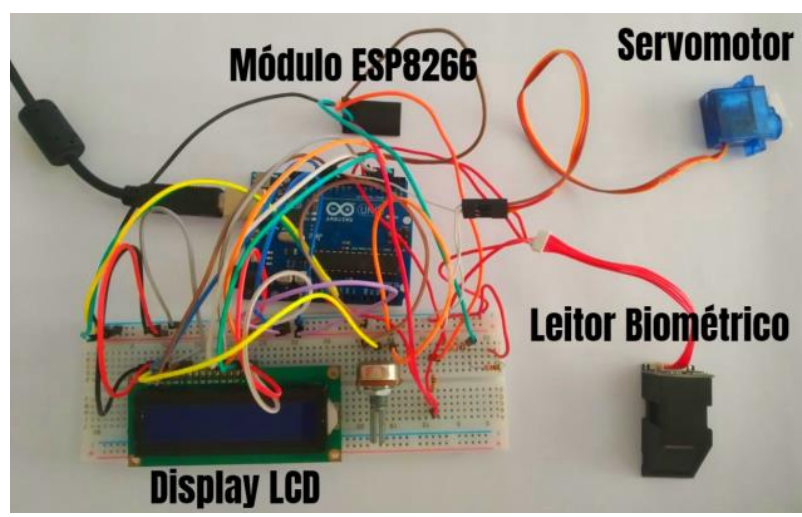

Fig. 2 Protótipo desenvolvido

O comportamento default do circuito desenvolvido define:

- Servomotor: posicionado no ângulo de zero graus, representando a trava da catraca.

- Display LCD: apresenta a mensagem "Aguardando Leitura".

- Leitor Biométrico e módulo ESP8266: ambos ativos e aguardando o próximo looping definido na programação do Arduino.

Quando um usuário classificado como "usuário comum", "idoso" ou "estudante" identifica-se no leitor biométrico e há crédito suficiente associado e não há nenhuma pendência (como a não aprovação do comprovante escolar no caso dos estudantes, por exemplo), o servomotor é movimentado $180^{\circ}$ de sua origem (representando a liberação da catraca) e o display LCD apresenta a mensagem "Liberado" seguido do valor pago pelo transporte.

Os casos de saldo insuficiente e pendência do comprovante escolar, possuem comportamento semelhante: o servomotor continua na posição de zero graus e no display LCD é exibido a mensagem "Bloqueado Saldo Insuf." e "Bloqueado Compr. Pendente.", respectivamente.

\subsection{Custos}

Graças à utilização dos conceitos estabelecidos pela Política Nacional de Resíduos Sólidos, os gastos referentes a este projeto limitam-se aos componentes eletrônicos. A Tabela 1, exibido a seguir, evidencia o preço de cada um dos produtos.

Tabela 1. Custo dos Componentes do Projeto

\begin{tabular}{|c|c|c|}
\hline $\begin{array}{c}\text { Nome do } \\
\text { Componente }\end{array}$ & $\begin{array}{c}\text { Descrição do } \\
\text { Componente }\end{array}$ & $\begin{array}{c}\text { Preço do } \\
\text { Componente }\end{array}$ \\
\hline $\begin{array}{c}\text { Placa Arduino } \\
\text { UNO R3 }\end{array}$ & Microcontrolador & $\mathrm{R} \$ 40,00$ \\
\hline Protoboard & $\begin{array}{c}\text { Placa com furos e } \\
\text { conexões condutoras } \\
\text { para montagem de } \\
\text { circuitos elétricos }\end{array}$ & $\mathrm{R} \$ 8,00$ \\
\hline
\end{tabular}

\begin{tabular}{|c|c|c|}
\hline $\begin{array}{l}\text { Módulo Leitor } \\
\text { Biométrico } \\
\text { Óptico Digital }\end{array}$ & $\begin{array}{l}\text { Leitor Biométrico de } \\
\text { Digitais projetado } \\
\text { para integração com } \\
\text { a placa Arduino }\end{array}$ & $\mathrm{R} \$ 60,00$ \\
\hline Monitor LCD & $\begin{array}{l}\text { Display composto de } \\
16 \text { colunas e duas } \\
\text { linhas, responsável } \\
\text { por apresentar } \\
\text { mensagens aos } \\
\text { usuários }\end{array}$ & $\mathrm{R} \$ 30,00$ \\
\hline Potenciômetro & $\begin{array}{l}\text { Componente } \\
\text { eletrônico que possui } \\
\text { resistência variável }\end{array}$ & $\mathrm{R} \$ 1,50$ \\
\hline Servomotor & $\begin{array}{l}\text { Motor que possui sua } \\
\text { posição angular } \\
\text { controlada por um } \\
\text { sinal PWM }\end{array}$ & $\mathrm{R} \$ 15,99$ \\
\hline $\begin{array}{l}\text { Módulo } \\
\text { ESP8266 }\end{array}$ & $\begin{array}{l}\text { Módulo wireless que } \\
\text { permite a integração } \\
\text { do Arduino com uma } \\
\text { rede } w i-f i\end{array}$ & $\mathrm{R} \$ 22,90$ \\
\hline Resistor & $\begin{array}{l}\text { Componente com a } \\
\text { finalidade de limitar, } \\
\text { diminuir ou dividir a } \\
\text { corrente ou tensão } \\
\text { em alguma parte do } \\
\text { circuito }\end{array}$ & $\mathrm{R} \$ 4,50$ \\
\hline Fios Jumper & $\begin{array}{l}\text { Fios utilizados para } \\
\text { conexões entre a } \\
\text { placa Arduino e os } \\
\text { demais componentes }\end{array}$ & $\mathrm{R} \$ 3,50$ \\
\hline
\end{tabular}

\section{CONCLUSÃO}

Este trabalho possibilitou entender a importância da evolução dos sistemas de identificação de pessoas, principalmente nas que envolvem transações monetárias. Pôde-se perceber, através de dados da Secretaria de Segurança Pública, a necessidade de melhorar a segurança nos transportes públicos para a diminuição de atividades ilícitas nos coletivos.

Para se atingir o propósito exposto, definiram-se dois objetivos específicos. O primeiro, de planejar e desenvolver a melhor técnica de identificação biométrica comportada pela plataforma Arduino. O segundo, de integrar o sistema $W E B$ desenvolvido com o protótipo montado.

Após a montagem do protótipo realizou-se diversos testes a fim de tentar simular possíveis falhas no protótipo montado. Observou-se que o protótipo atendeu às especificações relatadas ao longo deste documento: controlar o fluxo de usuários após sua identificação biométrica e analisar a situação de cada usuário de acordo com as informações cadastradas no banco de dados.

Como já esmiuçado no tópico de explicação técnica do protótipo, tem-se, de maneira geral, a utilização de dois módulos distintos do Arduino. Um módulo biométrico, 
responsável pela leitura das impressões digitais; e o módulo ESP8266 usado para integrar o circuito montado no Arduino e o sistema $W E B$.

Em consonância com o estudo elencado neste artigo percebese um potencial na utilização da biometria para o sistema de transporte público. Esta técnica permite maior segurança, devido a diminuição da circulação monetária nos coletivos, maior agilidade e conforto para o usuário que conta com um sistema completo de compra de créditos, podendo gerenciar o mesmo como quiser, além de eliminar diversos procedimentos burocráticos através do cadastro online.

\section{REFERÊNCIAS BIBLIOGRÁFICAS}

AZEVEDO, Miguel I. B. et al. Uma Análise Prática do Funcionamento e Aplicações de Automação com Foco na Área Residencial. In: Congresso Sul Brasileiro De Computação, 9., 2018, Castanhal. Anais SULCOMP. Castanhal: Unes, 2018. p. 1 - 8. Disponível em: $<$ http://periodicos.unesc.net/sulcomp/article/vie w/4809/4398>. Acesso em: 21 jan. 2019.

CONGRESSO DE ENSINO, PESQUISA E EXTENSÃO DA UEG, 4., 2017, Anápolis. Estudo de desenvolvimento economicamente eficiente na automação de sistemas computacionais digitais. Anápolis: Ueg, 2018. 9 p. Disponível em: <http://www.anais.ueg.br/index.php/cepe/article/view/10 642>. Acesso em: 20 jan. 2019.

GEMMER, Andréia Marisa; MUELLER, Sibele. PROGRAMAÇÃO WEB: Desenvolvimento de Website para um Escritório Contábil. Conexão, Itapiranga, v. 5, n. 1, p.1-19, dez. 2017. Disponível em: <http://revista.faifaculdades.edu.br/index.php/co nexao/article/view/306/229>. Acesso em: 21 jan. 2019.

GIL, A. Como elaborar Projetos de Pesquisa. 4. ed.

São Paulo: Atlas, 2002

MARQUES, Carlos et al. Desenvolvimento De Uma Aplicação De Controle De Presenças De Acadêmicos Com Uso De Reconhecimento Através De Biometria. Akrópolis - Revista de Ciências Humanas da Unipar, [s.1.], v. 25, n. 1, p.81-88, 20 mar. 2018. Universidade Paranaense. Disponível em: $<$ http://revistas.unipar.br/index.php/akropolis/art icle/view/6677>. Acesso em: 20 jan. 2019.

SCHUMPETER, Joseph A. Capitalismo, socialismo e democracia. São Paulo: Unesp Digital, 2017. Disponível em: <https://books.google.com.br/books?id=Cf1QD wAAQBAJ\&lpg=PT19\&dq=capitalismo\%20luc ro\&lr\&hl=pt-BR\&pg=PT6\#v=onepage $\& \mathrm{q}=$ capit alismo\%20lucro\&f=false $>$. Acesso em: 20 jan. 2019.

SILVA, Márcia Santos da; Filho, Venicio Siqueira. Biometria através de Impressão Digital. Cadernos UniFOA. Volta Redonda, Ano VI, n. 15, abril 2011. Disponível em: <http://www.unifoa.edu.br/cadernos/edicao/15/19.pdf $>$. Acesso em: 20 jan. 2019.

SILVA, Wellsson Rêgo. Biometria como ferramenta de inteligência: Importância da identificação criminal para a segurança pública. 2018. 33 f. Monografia (Especialização) - Curso de Curso de Especialização em Inteligência em Segurança, Universidade do Sul de Santa
Catarina, Paraíso, 2017. Disponível em: <https://www.riuni.unisul.br/handle/12345/4909 >. Acesso em: 20 jan. 2019. 